\title{
Why Men Commit Crimes (and Why They Desist)*
}

\author{
Satoshi Kanazawa \\ Indiana University of Pennsylvania \\ Mary C. STILL \\ Cornell University
}

\begin{abstract}
Hirschi and Gottfredson (1983) claim that the relationship between age and crime is similar in all social and cultural conditions and that no current sociological or criminological theory can account for this similarity. We introduce the new field of evolutionary psychology and extend Daly and Wilson's (1988) work on homicide to construct a general theory of male criminality, which explains why men commit violent and property crimes. The theory can also explain the age-crime curve. It might also account for some empirical anomalies such as why physically smaller boys are more delinquent, and why violent criminals desist more slowly.
\end{abstract}

In their highly influential 1983 article "Age and Explanation of Crime," Hirschi and Gottfredson claim that the relationship between age and crime is invariant across all social and cultural conditions at all times. In every society, for all social groups, for all races and both sexes, at all historical times, the tendency to commit crimes and other analogous, risktaking behavior rapidly increases in early adolescence, peaks in late adolescence and early adulthood, rapidly decreases throughout the 20s and 30s, and levels off during middle age. Figure 1 presents the typical age-crime curve (Hirschi and Gottfredson 1983: Figures 1, 5, 7-8). Although some of their claims have been controversial and there have been some minor variations observed around the invariant age curve (Greenberg 1985; Hirschi and Gottfredson 1985; Steffensmeier et al. 1989), the essential shape of the curve for serious interpersonal crimes remains uncontested in the criminological literature.

While Hirschi and Gottfredson claim that the age curve is invariant and holds in all societies at all times, they provide no explanations for this universal observation. They instead argue that no theoretical or empirical variable currently available in criminology can explain it. If the age-crime curve is truly constant across all populations, then any factor that varies across such populations cannot explain it. Just as a constant cannot explain a variable, a variable cannot explain a constant. The invariant age curve must be explained by something that is constant across all societies and cultures.

Some sociologists have provided just such explanations for why crime peaks in late adolescence and early adulthood. However, these explanations typically suffer from two

\footnotetext{
*We thank Deborah Blum, Mark E. Bouton, David M. Buss, Rebecca Lynn Churchill, Barbara J. Costello, Martin Daly, Lee Ellis, Paula England, David P. Farrington, Christine Horne, Allan Mazur, Paul J. Quirk, David C. Rowe, Anthony Walsh, and Margo Wilson for their comments on earlier drafts. This paper was completed while the first author was Summer Scholar in the Institute on Violence and the Life Course (co-directed by Kenneth A. Dodge and Robert J. Sampson) at the Center for Advanced Study in the Behavioral Sciences. He thanks the Andrew W. Mellon Foundation for the financial support. We dedicate this paper to Travis Hirschi. Travis' numerous achievements during his illustrious career as a criminologist include the publication of a highly influential book, Causes of Delinquency (1969) early in his career, the presidency of the American Society of Criminology in 1983, and the very successful collaboration with Michael R. Gottfredson later in his career on many books and articles, on one of which we focus in this paper. One of the few low points in his career was having to serve on the dissertation committee of the first author. Direct all correspondence to: Satoshi Kanazawa, Department of Sociology, Indiana University of Pennsylvania, Indiana, PA 15705-1087. E-mail: Kanazawa@ grove.iup.edu.
} 


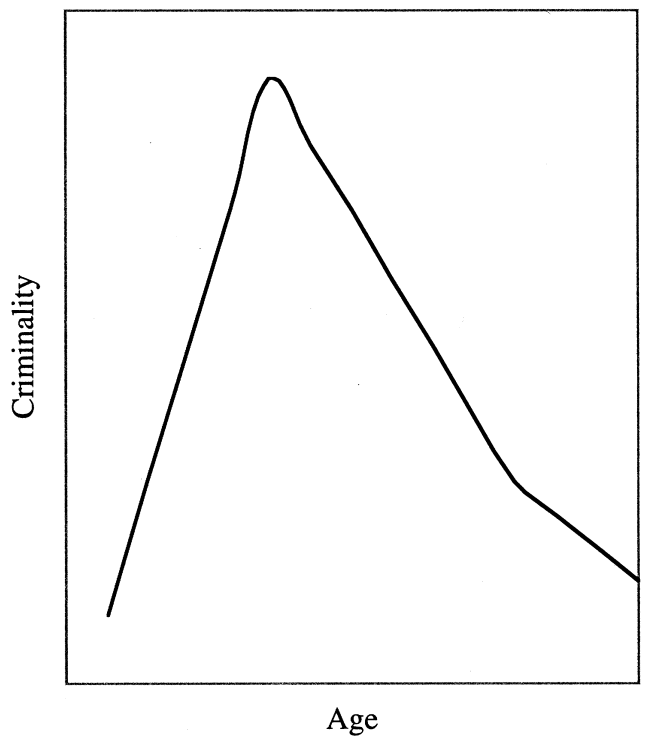

Figure 1. The Age-Crime Curve

problems. The first is that the explanation simply begs the question. For instance, Gove (1985: 134) notes that "many adolescents find their roles lacking in intrinsic rewards and turn to sensate activities to achieve a sense of self." Gove argues that this "need for stimulation," combined with heightened levels of testosterone, leads many adolescents to commit crime. But why is it that adolescents find criminal activities stimulating and fulfilling but adults do not? Why is it that they have a need for stimulation that adults (presumably) do not?

Another problem with these explanations is that their applicability is limited to contemporary industrial societies. Gove (1985: 138) and Walsh (1995: 184-85) explain crime among adolescents as a function of the combination of high autonomy and low responsibility during the teenage years. Such a combination accurately describes teenagers in the United States and other western nations today, and thus Gove and Walsh might be able to explain the relationship between age and crime in the western society in the latter half of the twentieth century. However, if Hirschi and Gottfredson are right and the age-crime curve is universal in all societies at all times, then it should hold both in the developing nations today and the western nations in the past. Any explanation applicable only to the contemporary western societies is inadequate.

Other explanations of the age-crime curve tend to be incomplete. Grogger (1998) presents an explicitly decision-theoretic model in which actors choose between crime and labor market as alternative means of earning money. Among other things, he uses his model to explain the age-crime curve. While his model successfully explains why property crime precipitously drops in early adulthood (while their market wages and opportunity costs of crime rapidly increase), it cannot explain why crime participation increases during early to middle adolescence. Nor can his model explain violent crimes. There has therefore been no satisfactory theory of crime that can explain all aspects of the curve (both the incline and decline over the life course) and is applicable to all crimes in all societies at all times.

In this paper, we will first introduce the emerging field of evolutionary psychology (Barkow, Cosmides and Tooby 1992), and then propose a theory of male criminality derived 
from this perspective. The theory explains, among other things, the Hirschi-Gottfredson age-crime curve. By the age-crime curve we mean the relationship between age and criminality where: 1) criminality rapidly rises during adolescence; 2) it peaks in late adolescence or early adulthood; 3) it rapidly decreases during adulthood; and 4) it remains very low for the rest of the life. While the age-crime curve is not exactly identical for all crimes in all societies (Greenberg 1985; Steffensmeier et al. 1989), these four features are present for all serious interpersonal crimes (except such minor crimes as gambling, fraud, and drug use) in all societies for which data are available. We seek to explain these four features of the age-crime curve.

Before we present the theory, however, it is important to state its limitations explicitly. First, ours is a theory of criminality, not crime or criminal behavior. Crime is a function of criminality (propensity to commit crime) and external factors (opportunities and constraints) (Hirschi and Gottfredson 1986: 58). As the routine activity approach (Cohen and Felson 1979) demonstrates, whether someone with criminal propensities actually commits a crime depends largely on the circumstances, and one of us has elsewhere explained differential crime rates among nations in terms of such situational and institutional factors (Hechter and Kanazawa 1993). Our current theory only explains why people want to commit crimes, not whether they actually do so.

Second, ours is a theory of male criminality, and it does not explain female criminality at all. To the extent that women commit crimes (although women commit very few serious crimes worldwide), our theory is not able to explain it. However, given how inherently different men and women are, we would not expect men and women to commit crimes for the same reason. ${ }^{1}$ Parsimony is not as important a criterion for theory as logic and evidence (Kanazawa 1998: 197n). Our theory only explains some of the reasons why men might want to commit crimes.

Third, our theory explains intraindividual variations in criminality, not interindividual variations. We explain why men at certain ages or in certain life-stages are more criminal than the same men would otherwise be. Our evolutionary psychological theory cannot explain why some men are inherently and consistently more criminal throughout their lives than others. In Moffitt's (1993) terminology, our theory explains the age-crime curve of those who are criminal only during adolescence, not why some people are criminal only during adolescence and others are throughout their lives. Behavior-genetic (Ellis and Walsh 1997; Rowe, Vazsonyi and Figueredo 1997) and developmental (Moffitt 1993; Patterson and Yoerger 1993) theories of crime, among others, account for such interindividual differences in criminality.

\section{PRINCIPLES OF EVOLUTIONARY PSYCHOLOGY}

Because evolutionary psychology is a very new field and because sociologists in particular are unlikely to be familiar with it, we will first explain its foundational principles before we proceed to our theory derived from this perspective. ${ }^{2}$

Evolutionary psychology seeks to discover universal human nature, which is a collection of domain-specific psychological mechanisms. A psychological mechanism is an information-processing procedure or decision rule that natural selection has equipped humans to possess in order to solve a particular adaptive problem (a problem of survival or reproduction). Unlike decision rules in microeconomic subjective expected utility maximiza-

\footnotetext{
${ }^{1}$ We thank Joanne Savage for making this point.

${ }^{2}$ Excellent introductions to evolutionary psychology include Barkow et al. (1992), Buss (1994, 1995, 1999), Ridley (1993), and Wright (1994).
} 
tion theory or game theory, however, psychological mechanisms mostly operate behind our conscious thinking.

Male sexual jealousy is an example of an evolved psychological mechanism (Daly, Wilson and Weghorst 1982). Because gestation in human and most other mammalian species occurs inside the female body, males of these species can never be certain of the paternity of their mates' offspring while females are always certain of their maternity. In other words, the possibility of cuckoldry exists only for males. Men who are cuckolded and invest their resources in the offspring of other men end up wasting these resources, and their genes will not be represented in the next generation. Men therefore have a strong reproductive interest in making sure that they will not be cuckolded while women do not share this interest. Accordingly, men have been selected to possess a psychological mechanism that makes them extremely jealous at even the remotest possibility of their mates' sexual infidelity. The psychological mechanism of sexual jealousy solves men's adaptive problem of paternal uncertainty. The same psychological mechanism often leads to men's attempt at mate guarding in order to minimize the possibility of their mates' sexual contact with other men, sometimes with tragic consequences (Buss 1988; Buss and Shackelford 1997).

While men and women are the same in the frequency and intensity of their jealousy in their romantic relationships (White 1981; Buunk and Hupka 1987), there are clear sex differences in what triggers jealousy. There is both survey and physiological evidence from different cultures to show that men get jealous of their mates' sexual infidelity with other men, underlying their reproductive concern for cuckoldry. In contrast, women get jealous of their mates' emotional involvement with other women because emotional involvement often leads to diversion of their mates' resources from them and their children to their romantic rivals (Buss et al. 1992; Buss et al. 1999).

Note that we do not consciously choose or decide to get jealous. We just get jealous under some circumstances, in response to certain predictable triggers, but otherwise don't know why. However, what triggers jealousy is always understandable to others, and these triggers are cross-culturally constant (Thiessen and Umezawa 1998); otherwise, no romance novels or romantic comedies would ever become international hits. Evolutionary psychology explains human behavior in terms of these evolved psychological mechanisms, and the preferences, desires, and emotions that they produce in us.

Evolutionary psychology is premised on two broad generalizations. The first generalization, to put it bluntly, is that there is nothing special about Homo sapiens. To put it more precisely, "certainly we are unique, but we are not unique in being unique. Every species is unique and evolved its uniqueness in adaptation to its environment. Culture is the uniquely human way of adapting, but culture, too, evolved biologically" (van den Berghe 1990: 428). Human beings are just like other animal species (Betzig 1997; de Waal 1996; Maryanski and Turner 1992), and all the laws of nature, in particular, the laws of evolution by natural and sexual selection, apply as much to humans as they do to other species. The second broad generalization is that there is nothing special about the brain as a body part; it is just like the hand or the pancreas or any other body part. Just as a long history of evolution has shaped the hand or the pancreas to perform a specific function, so has evolution shaped the brain to perform certain tasks (solving adaptive problems).

The second generalization leads to a very important implication of evolutionary psychology. Just as the basic shape and functions of the hand and the pancreas have not changed since the end of the Pleistocene epoch about 10,000 years ago, the basic functioning of the brain has not changed very much in the last 10,000 years. The human body (including the brain) evolved over millions of years during the Pleistocene epoch in the African savanna where humans lived during most of this time (Maryanski and Turner 


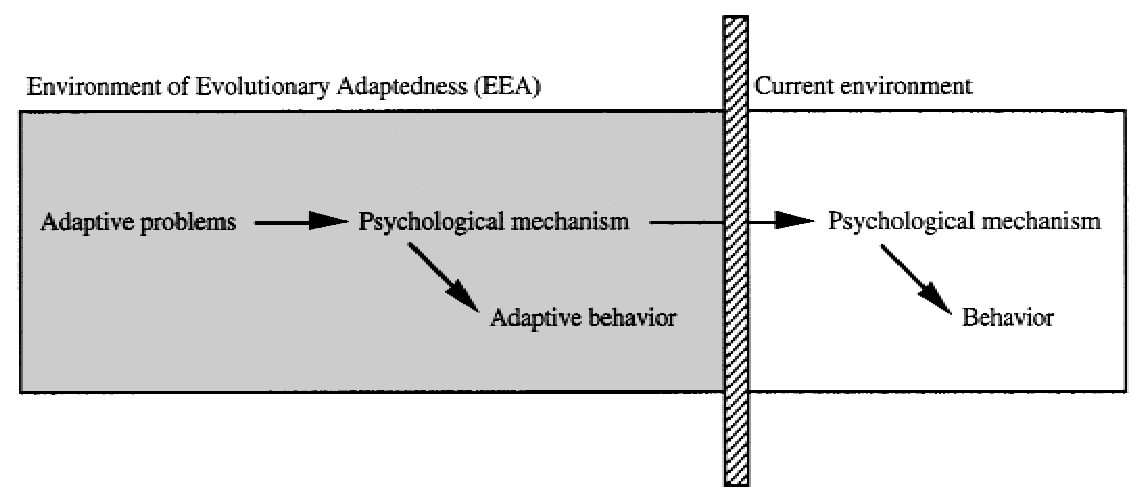

Figure 2. The Basic Theoretical Structure of Evolutionary Psychology

1992: 69-90). This environment-African savanna where humans lived in small bands of fifty or so related individuals as hunter-gatherers ${ }^{3}$ - is called the environment of evolutionary adaptedness (EEA) (Bowlby 1969) or ancestral environment, and it is to the EEA that our body (including the brain) is adapted.

Figure 2 presents the basic theoretical structure of evolutionary psychology. It argues that an adaptive problem leads to an evolved psychological mechanism, which then usually leads to adaptive (fitness-maximizing) behavior in the EEA. Evolutionary psychology assumes that most behavior in the EEA maximizes inclusive fitness of the actor. However, it recognizes that our current environment may be radically different from the EEA, yet our psychological mechanisms (just like our hands and our pancreas) are still the same as they were in the EEA and produce the same behavior as they did in the EEA. This leads to the distinct possibility that our behavior in our current environment might be completely maladaptive. To the extent that our current environment is different from the EEA (to which all psychological mechanisms are adapted), evolutionary psychology would predict that our current behavior is maladaptive.

Recall the example of male sexual jealousy as an evolved psychological mechanism. It solved the adaptive problem of successful reproduction in the EEA by allowing men who possessed it to maximize paternal certainty and minimize the possibility of cuckoldry. Their sexual jealousy was therefore fitness maximizing in the EEA. However, sex and reproduction are often separated in the current environment (in that many episodes of copulation do not lead to reproduction). There is an abundance of reliable methods of birth control in industrial societies, and many married women use the birth control pill. For these women, sexual infidelity does not lead to childbirth, and their mates will not have to waste their resources on someone else's offspring. In other words, the original adaptive

\footnotetext{
${ }^{3}$ As a first approximation, it might be useful to think of the EEA as the African savanna during the Pleistocene epoch because this is indeed where many psychological mechanisms evolved. Technically, however, the EEA "is not a place or a habitat, or even a time period. Rather, it is a statistical composite of the adaptation-relevant properties of the ancestral environments encountered by members of ancestral populations, weighted by their frequency and fitness-consequences" (Tooby and Cosmides 1990: 386-387). In other words, the EEA might be different for different adaptations.

For instance, in order to pinpoint the EEA for male sexual jealousy as an adaptation, we need to consider the entire period of evolution from the time when males did not have sexual jealousy (this is likely to be long before they were human) until the time when all human males had the psychological mechanism of sexual jealousy that they currently possess. This is likely the period during which cuckoldry was a problem for paternal certainty. Further, we must emphasize the period during which cuckoldry was more prevalent (weight by frequency) and during which males with sexual jealousy had particularly greater reproductive success than those without it (weight by fitness-consequences).
} 
problem no longer exists. Yet men still possess the same psychological mechanism to make them jealous at the possibility of their mates' sexual infidelity and to compel them to guard their mates to minimize the possibility of cuckoldry. No man would ever be comforted by the fact that his adulterous wife was on the pill at the time of her sexual infidelity.

Further, because our environment is so vastly different from the EEA, we now face a curious situation where those who behave according to the dictates of the evolved psychological mechanism are often worse off in terms of survival and reproduction. Extreme forms of mate guarding, such as violence against mates or romantic rivals, are felonies in most industrial nations. Incarceration, and consequent physical separation from their mates, to which such violence can lead, does everything to reduce the reproductive success of the men. Just as the intense use of our hands (which were designed for primitive activities in the EEA) for typing on a QWERTY keyboard leads to carpal tunnel syndrome, uncritically following the emotions and desires created in us by our evolved psychological mechanisms often leads to maladaptive behavior.

This distinction between the EEA and our current environment is crucial for our discussion of crime. Given that every industrial society has a reasonably efficient system of criminal justice, which catches and punishes a large proportion of felons, committing serious violent and property crimes in our current environment could seldom be adaptive. Criminal punishment (fines and jail terms) hinders both survival and successful reproduction. Yet men's evolved psychological mechanisms may still compel them to commit crimes because there were no police or courts in the EEA.

\section{EVOLUTIONARY PSYCHOLOGICAL THEORY OF MALE CRIMINALITY}

In their comprehensive study of homicide from the evolutionary psychological perspective, Daly and Wilson (1988: 137-161) note that humans throughout their evolutionary history were effectively polygynous. In a polygynous breeding system, some males monopolize reproductive access to all females while other males are left out; in such a system, some males don't get to reproduce at all while almost all females do. This inequality of reproductive success (or fitness variance) between males and females makes males of species with polygynous breeding systems (such as humans) highly competitive in their effort not to be left out of the reproductive game. This intrasexual competition among men leads to a high level of violence among them, and the large number of homicides between men (compared to the number of homicides between women) is a direct result of this intrasexual competition and violence.

In particular, Daly and Wilson (1988: 123-136) note that most homicides between men originate from what Wolfgang (1958) calls "trivial altercations." A typical homicide begins as a fight about trivial matters of honor, status, and reputation between men (such as when one man insults another). Fights escalate because neither is willing to back down, until they become violent and one of the disputants ends up dead. Because women prefer to mate with men of high status and good reputation (Buss 1994: 19-48), men's status and reputation directly correlate with their reproductive success. Men are therefore highly motivated (albeit unconsciously) to protect their honor, and often go to extreme lengths to do so, compelled by their evolved psychological mechanisms. Daly and Wilson thus explain homicides between men in terms of their (largely unconscious) desire to protect their status and reputation in their attempt to gain reproductive access to women.

One can easily extend this analysis to other forms of interpersonal violence among men. Less serious violent crimes, such as assault and battery, can have the same underlying motive to protect one's status and reputation in an effort to gain reproductive access. Whether the violence results in a death (making the crime homicide) or an injury (making 
the crime serious assault) is often beyond the control of the offender. It crucially depends on the reaction of the victim and what transpires between the offender and the victim in the course of the conflict, as well as other fortuitous circumstances such as the presence of others, distance to the nearest hospital, and the physical strength of the victim. If men can be driven to kill in order to protect their status and reputation, they can also be driven to commit less serious acts of violence.

Rape appears to be an exception to this reasoning because, unlike murders and assault, the victims of rape are women and therefore there is no intrasexual competition for status and reputation. However, the same psychological mechanism that compels men to gain reproductive access to women can motivate men to commit rape. Predatory rapists are overwhelmingly men of lower class and status who have very dim prospects to gain legitimate reproductive access to women (Thornhill and Thornhill 1983). While it is not a manifestation of intrasexual competition and violence, rape might also be motivated by men's psychological mechanism that compels them to gain reproductive access to women when they don't have the legitimate means to do so (Buss 1994: 166).

One can also extend the same analysis to property crimes. If women prefer to mate with men with more resources, then men can increase their reproductive success by acquiring material resources. Material resources in traditional societies, however, tend to be concentrated in the hands of elder men. Younger men are often excluded from attaining them through legitimate means and must therefore resort to illegitimate means. One method of doing so is to appropriate someone else's resources by stealing them. Thus, the same psychological mechanism that creates the motive for violent crime can also compel men to commit property crimes.

Our suggestion that men steal in order to attract women might appear counterintuitive since theft and other forms of resource malappropriation are universally condemned in human societies. It is quite possible, however, that the psychological mechanism that compels young males to commit violent and property crimes developed in our ancestors in the evolutionary history before the ape-human split (5-8 million years ago), even before the ape-monkey split (15-20 million years ago). In fact, our theory logically requires that the crucial psychological mechanism emerge before the informal norms against violence and theft did; otherwise, violent competition and accumulation of resources through theft would not lead to higher status and reproductive success for males because they would be ostracized for violating the norms. ${ }^{4}$ We believe that the norms against violence and theft might have developed in reaction to the psychological mechanism which compelled young males to engage in violence and theft. The fact that violent and predatory acts that would be classified as criminal if committed by humans are quite common among nonhuman species that do not have informal norms against such acts (Ellis 1998), increases our confidence in this speculation.

Note that it is immaterial to our theory that most male criminals do not cite reproductive success as a motive for their crimes. For psychological mechanisms usually operate at the unconscious level. Our contention is that men under some circumstances commit crimes because they want to (making them highly criminal), and they want to commit crimes because something compels them to. We contend that that something is the evolved psychological mechanism that predisposes all men to seek reproductive success. The men themselves are completely unaware of the evolutionary logic behind their motives.

\section{HOW THE THEORY EXPLAINS THE AGE-CRIME CURVE}

There are reproductive benefits to men of intense competitiveness. Those who are highly competitive act violently toward their male rivals. Their violence serves the dual function

\footnotetext{
${ }^{4}$ We thank Barbara J. Costello and Allan Mazur for independently making this point.
} 
of protecting their status and honor and discouraging or altogether eliminating their rivals from competition for mates. Their competitiveness also compels them to accumulate resources to attract mates by stealing from others. The same psychological mechanism induces males who cannot gain legitimate access to females to do so illegitimately through forcible rape. Figure 3(a) presents a hypothetical curve, depicting the relationship between male's age and benefits from competition. There are no reproductive benefits from competition (violence and theft) before puberty because prepubertal males are not able to translate their competitive edge into reproductive success. With puberty, however, the benefits of competition skyrocket. Once the males are reproductively capable, every act of violence and theft can potentially increase their reproductive success. The benefits of competition stay high after puberty for the remainder of their lives since human males are reproductively capable for most of their adult lives.

This is not the whole story, however. There are also costs associated with competition. Acts of violence can easily result in their own death or injury, and acts of resource appropriation can trigger retaliation from the rightful owners of the resources. Males' reproductive success is obviously reduced if the competitive acts result in their death or injury.

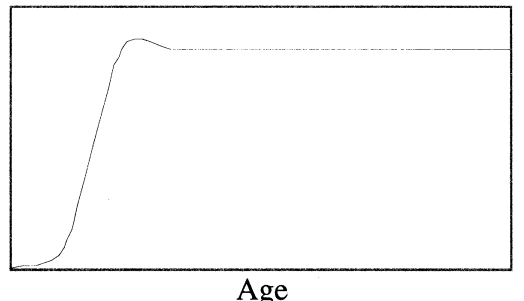

(a) Reproductive Benefits of Competition

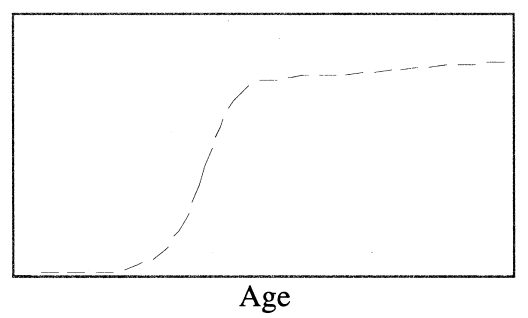

(b) Reproductive Costs of Competition

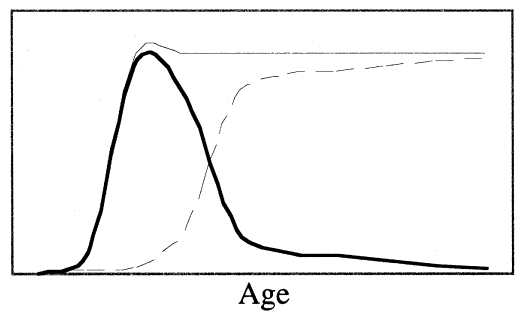

(c) Propensity Toward Competition $=$ Benefits - Costs

Figure 3. The Benefits and Costs of Competition and the Age Crime Curve 
Figure 3(b) presents a hypothetical curve depicting the costs of competition as a function of age. Before males start reproducing (before their first child), there are few costs of competition. True, being competitive might result in their death or injury, and they might therefore lose in the reproductive game. However, they also lose by not competing. If they don't compete for mates in a polygynous breeding system, they'll be left out of the game and end up losing as a result. In other words, young men might lose if they were competitive, but they would definitely lose if they weren't. So there's little cost to being competitive even at the risk of death and injury; the alternative is worse in terms of reproductive success.

The cost of competition, however, dramatically rises with the birth of the first (and subsequent) children. True, they still benefit from competition (as Figure 3(a) shows) because such acts of competition might attract additional mates even after their initial reproduction. However, males' energies and resources are put to better use by protecting and investing in their existing children. If the males die or get injured in their acts of competition, their existing children will suffer. They might starve or fall victim to predation by others. The costs of competition therefore rapidly increase after the birth of the first child, which usually happens several years after puberty because males need some time to accumulate sufficient resources to attract their first mate. (Nonetheless, in the absence of artificial means of contraception, reproduction probably began at a much earlier age than it does today.) There is therefore a gap of several years between the rapid rise in the benefits of competition and the similarly rapid rise in its costs.

Figure 3(c) depicts a curve that represents the mathematical difference between the benefits and the costs of competition. The curve closely resembles the typical age-crime curve shown in Figure 1. We contend that male criminality varies as it does over the life course because it represents the difference between the benefits and costs of violence and theft. It is important to point out, however, that, unlike actors in decision theories in microeconomics, males in our theory do not make these calculations consciously. The calculation has been performed by natural and sexual selection, so to speak, which then equips male brains with a psychological mechanism to compel them to be increasingly competitive in their immediate postpubertal years and to make them less competitive right after the birth of the first child. Men simply don't feel like acting violently or stealing, or they just want to settle down, after the birth of the child, but they do not exactly know why.

Fluctuating levels of testosterone might provide the biochemical microfoundation for this psychological mechanism. David Gubernick's unpublished experiment (discussed in Blum 1997: 116) demonstrates that expectant fathers' testosterone levels precipitously fall immediately after the birth of their children. If high levels of testosterone predispose men to be more competitive and violent, then the sudden drop in testosterone after the birth of their children might provide the biochemical reason why men's psychological mechanism to commit crime "turns off" when they become fathers. Mazur and Michalek's (1998) finding that marriage decreases, and divorce increases, testosterone levels in men provides a similar microfoundation for the commonly observed negative effect of marriage on criminality (Laub, Nagin and Sampson 1998).

Now, given that human society was always mildly polygynous, there were many men who did not succeed at securing mates and reproducing. These men had everything to gain and nothing to lose by remaining competitive and violent for their entire lives. However, we are not descended from these men. As Buss (1994: 114) reminds us, all of us are disproportionately descended from men and women who were very successful at reproduction. Contemporary men therefore did not inherit the psychological mechanism that forces them to stay competitive and keep trying to secure mates for their entire lives. 


\section{OTHER EMPIRICAL IMPLICATIONS OF THE THEORY}

Besides providing a possible explanation for the age-crime curve, our evolutionary psychological theory of male criminality has other empirical implications. First, the theory would predict that males commit an overwhelming majority of all violent and property crimes in every society. Since only men have the evolved psychological mechanism that makes them extremely competitive with each other and compels them to seek reproductive success through interpersonal violence and appropriation of resources, and since the same psychological mechanism is absent in women (in a polygynous breeding system where they need not compete for men as intensely (Daly and Wilson 1988: 137-161)), our theory would predict that only men would commit crimes. In fact, our theory is incapable of explaining why women commit crimes. To the extent that our theory is truer than other theories of criminality, and to the extent that the evolved psychological mechanism that it posits has a greater effect on criminality than other factors do, then the overwhelming majority of criminals should be males.

With only a single exception (Syria), ${ }^{5}$ men are responsible for an overwhelming majority of all serious crimes in every single society in the world for which data are available (International Criminal Police Organization, various years). Worldwide, women account for $6.51 \%$ of murderers, $1.31 \%$ of rapists, $12.80 \%$ of those charged with serious assault, and $7.26 \%$ of robbers. No cultural or social factors can explain this overwhelming male criminality worldwide. Cultural and social factors (whatever they are) by definition vary across cultures and societies, and, once again, a variable cannot explain a constant. It is difficult to think of a social or cultural factor common to Switzerland and Swaziland, Algeria and Argentina, the United States and the United Arab Emirates. Yet in all of these countries, men commit almost all of the serious crimes. The reason must be something constant across all human males.

Another implication of our theory is that young men commit an overwhelming majority of all violent and property crimes in every society. This is a restatement of Hirschi and Gottfredson's (1983) invariance hypothesis, and our theory not only explains the agecrime curve but also predicts that the relationship between age and criminality is similar in all societies at all times. The proportion of young men aged 15-34 in fact strongly predicts the incidence of murder, rape, assault, and robbery across all societies of the world. (The results of multiple regression analyses are available from the authors upon request.)

A third implication of our theory is that sexual competition increases men's tendency to commit violent and property crimes in every society. If men commit crimes as a byproduct of their attempt to compete against other men to gain reproductive access to women, then it follows that their tendency to commit crimes should increase with the degree of intrasexual competition. One factor that influences sexual competition is the institution of marriage. While humans in the EEA mostly practiced polygyny, many contemporary societies have the monogamous institution of marriage. Monogamy, by prohibiting even the richest and higheststatus men from acquiring more than one wife legally, greatly reduces the extent of sexual competition among the rest of the men. Thus, we expect the monogamous institution of marriage to reduce crimes; conversely, we expect the polygynous institution of marriage to increase crimes. The extent of polygyny in society indeed predicts the incidence of murder, rape, and robbery across all societies. In particular, the most polygynous societies in the world (such

\footnotetext{
${ }^{5}$ According to the INTERPOL data, a significant minority or even majority of offenders of all serious felonies in Syria year after year are women. We are frankly baffled by these statistics; however, it is very difficult for us to believe that Syrian women, alone in the whole world, are genuinely more criminal than women elsewhere. We strongly suspect that there are some cultural or institutional reasons for these peculiar statistics (such as women routinely taking the fall for crimes committed by their husbands or fathers), and have asked several Syrian experts for possible explanations. However, we have not been successful in finding one so far.
} 
as Swaziland, Lesotho, Botswana, Zimbabwe, Papua New Guinea, and Fiji) simultaneously have some of the highest murder rates in the world.

A fourth implication of our theory is that married men have less tendency to commit violent and property crimes in every society. If men commit crimes because their evolved psychological mechanism compels them to compete with each other to gain reproductive access, then the successful attainment of this goal should make them less likely to commit crimes. Although a true mark of reproductive success is reproduction, not marriage per se, the two are inextricably linked in the EEA where there was no artificial means of contraception (and hence in the human brain which is adapted to the EEA). We would therefore expect that, ceteris paribus, married men are less likely to commit violent and property crimes than unmarried men.

Daly and Wilson's (1988: 168-170) study of homicides in Detroit shows that murderers (and their victims) are significantly more likely to be unmarried than the population average for the age group. Sampson and Laub's (1993: 204-242) and Laub, Nagin and Sampson's (1998) analyses of longitudinal data on delinquent boys in Massachusetts demonstrates that strong marriage often leads to desistance among former delinquents. Farrington and West's (1995) longitudinal data from South London show a similar effect of marriage on desistance. In fact, across all societies, the proportion of adult males who are unmarried predicts the incidence of murder, rape, and robbery.

\section{DISCUSSION}

Extending Daly and Wilson's (1988) work on homicide, we have constructed a general evolutionary psychological theory of male criminality. The theory posits that the intense intrasexual competition for mates among young men has produced a psychological mechanism which compels them to commit interpersonal violent crimes and property crimes in their attempt to gain reproductive access to women. (Psychological mechanisms evolved in the EEA, millions of years ago, when there were no police, courts, or any other thirdparty intervention in interpersonal conflict.) Natural and sexual selection has calibrated this psychological mechanism to take into account both the benefits and costs of competition as a function of the men's age and life-stage. As a result, men become rapidly more criminal immediately following puberty, and become equally rapidly less criminal around the time of the birth of their first child (which probably happened only a few years after their puberty in the EEA).

Our theory, which posits a single psychological mechanism as the cause of all forms of criminality, not only explains Hirschi and Gottfredson's (1983) age-crime curve, but is also consistent with their more recent work on the generality of crime and deviance (Gottfredson and Hirschi 1990; Hirschi and Gottfredson 1994) and with the fact that criminals do not specialize. Men who commit one kind of crime are also more likely to commit other kinds of crime and risk-taking behavior. Our theory can explain why the psychological mechanism of young men might compel them to increase their prospect of reproductive success by any means available.

In addition to the four empirical implications, our theory can account for other known facts about crime. For instance, our theory would predict that lower-class men would commit more violent and property crimes than middle-class men. This is because lowerclass men lack the resources and status to attract women, and, therefore, they need to be more competitive and to acquire more material resources in order to achieve reproductive success. Although there has been a considerable controversy within criminology on the issue of the relationship between class and criminality (Tittle, Villemez and Smith 1978), the current consensus appears to be that there is a significant negative relationship between 
social class and the commission of serious violent and property crimes (Braithwaite 1981; Ellis 1988: 532-533; Hagan, Gillis, and Brownfield 1996: 1-15).

Of particular interest in this connection is Stark's (1979) finding that, while parents' social class does not predict juvenile delinquency, juveniles' own status within their peer groups does. In other words, juvenile boys who enjoy high status within the school (by being popular and reputable) are less likely to commit delinquency than boys who do not enjoy such high status. To the extent that the correlation between parents' and juveniles' class positions is not perfectly positive, our theory would also predict that it is the juvenile boys' own prospect for reproductive success that switches on and off their evolved psychological mechanism. The star quarterback or the class president is more likely to get dates and have steady girlfriends than a secretary-treasurer of a chess club, no matter what their respective parents' class positions.

Our theory can also account for some seeming empirical anomalies in the criminological literature. For instance, Farrington's longitudinal data on boys in London demonstrate that physically smaller boys are significantly more likely to be delinquent (Farrington 1992: Table 11.2(g)) or to perpetrate soccer violence (Farrington 1994: Table 2). This finding contradicts the common perception that criminals are muscular mesomorphs. Why would smaller boys be more delinquent and violent?

It turns out that there is a significant positive correlation between height or body size and status dominance across all species (Ellis 1994); taller or larger males are more likely to be dominant in social hierarchies than smaller males. Smaller boys therefore begin their race toward reproductive success with a greater deficit than their larger classmates, much as do boys who are unpopular in schools. Our evolutionary psychological theory of male criminality therefore predicts that both smaller and unpopular boys will be more criminal and violent than their larger or popular counterparts in order to overcome this deficit. It further predicts that the same boys might desist from crime and violence once they become popular or larger in size.

There are other empirical anomalies that our theory can explain in the typical "exception that proves the rule" fashion. For instance, it has been known that violent criminals desist more slowly than property criminals; the age-crime curve for violent offenses has a less steep decline during adulthood than that for property offenses (Blumstein 1995: Figures $2 \mathrm{a}$ and $2 \mathrm{~b}$ vs. Figures $3 \mathrm{a}$ and $3 \mathrm{~b}$ ). If the age-crime curve is truly invariant for all offenses (as Hirschi and Gottfredson (1983) claim and we concur), and if our theory posits a single psychological mechanism for both violent and property crimes, how can we explain slower desistance (proportionately more criminals in their older years) for violent offenses?

An analysis of the 1996 Supplementary Homicide Reports, compiled by the Federal Bureau of Investigation, reveals that older violent criminals might be qualitatively different from younger violent criminals in terms of whom they victimize. The proportion of males among murder victims declines monotonically with the murderer's age: For murderers aged $15-19,86.3 \%$ of the victims are males; for murderers aged $65-69$, only $51.4 \%$ of the victims are males. Both Daly and Wilson (1988) and our theory would predict that men kill other men and women for different reasons. Killing men is a function of status and resource competition toward reproductive success mostly by younger men. As such, we would expect it to follow the same age-crime curve for property crime, and the SHR data seem to indicate that this might be the case. In contrast, killing women is an extension of mate-guarding (Buss and Shackelford 1997; Daly, Wilson and Weghorst 1982). Men become morbidly jealous when their mates spend time with other men, and in their attempt to control their mates' behavior, sometimes through violent means, many of them end up injuring or killing their mates (Daly and Wilson 1988: 187-219). Because men of all ages are more motivated to guard reproductively fertile younger women than older women, 
killing women is better predicted by women's age, not men's (Daly and Wilson 1988: 205-208). In other words, men, regardless of their age, are compelled to guard their young mates through violent means and occasionally end up killing them. Since many older men in their 40's and 50's are married to younger women (sometimes considerably younger), some of these men are expected to kill women (their mates) in their fits of morbid jealousy and thus deviate from the typical age-crime curve. We therefore predict that the age-crime curve for murder will be similar to the one for property crime if the offense is limited to male victims, and the 1996 Supplementary Homicide Reports data support our prediction.

\section{REFERENCES}

Barkow, Jerome H., Leda Cosmides, and John Tooby (editors.) 1992. The Adapted Mind: Evolutionary Psychology and the Generation of Culture. New York: Oxford University Press.

Betzig, Laura. 1997. "Introduction: People Are Animals." Pp. 1-17 in Human Nature: A Critical Reader, edited by Laura Betzig. New York: Oxford University Press.

Blum, Deborah. 1997. Sex on the Brain: The Biological Differences Between Men and Women. New York: Penguin.

Blumstein, Alfred. 1995. "Youth Violence, Guns, and the Illicit-Drug Industry." Journal of Criminal Law and Criminology 86:10-36.

Bowlby, John. 1969. Attachment and Loss. Volume 1: Attachment. New York: Basic.

Braithwaite, John. 1981. "The Myth of Social Class and Criminality Reconsidered." American Sociological Review 46:36-57.

Buss, David M. 1988. "From Vigilance to Violence: Tactics of Mate Retention.” Ethology and Sociobiology 9 : 291-317.

Buss, David M. 1994. The Evolution of Desire: Strategies of Human Mating. New York: BasicBooks.

Buss, David M. 1995. "Evolutionary Psychology: A New Paradigm for Psychological Science.” Psychological Inquiry 6:1-30.

Buss, David M. 1999. Evolutionary Psychology: The New Science of the Mind. Boston: Allyn and Bacon.

Buss, David M., Randy J. Larsen, and Drew Westen. 1992. "Sex Differences in Jealousy: Evolution, Physiology, and Psychology." Psychological Science 3:251-55.

Buss, David M. and Todd K. Shackelford. 1997. "From Vigilance to Violence: Mate Retention Tactics in Married Couples." Journal of Personality and Social Psychology 72:346-61.

Buss, David M., Todd K. Shackelford, Lee A. Kirkpatrick, Jae C. Choe, Mariko Hasegawa, Toshikazu Hasegawa, and Kevin Bennett. 1999. "Jealousy and the Nature of Beliefs about Infidelity: Tests of Competing Hypotheses about Sex Differences in the United States, Korea, and Japan.” Personal Relationships 6:125-50.

Buunk, Bram and Ralph B. Hupka. 1987. "Cross-Cultural Differences in the Elicitation of Sexual Jealousy." Journal of Sex Research. 23:12-22.

Cohen, Lawrence E. and Marcus Felson. 1979. "Social Change and Crime Rate Trends: A Routine Activity Approach." American Sociological Review 44:588-608.

Daly, Martin and Margo Wilson. 1988. Homicide. New York: De Gruyter.

Daly, Martin, Margo Wilson, and Suzanne J. Weghorst. 1982. "Male Sexual Jealousy.” Ethology and Sociobiology 3:11-27.

De Waal, Frans. 1996. Good Natured: The Origins of Right and Wrong in Humans and Other Animals. Cambridge, MA: Harvard University Press.

Ellis, Lee. 1988. "The Victimful-Victimless Crime Distribution, and Seven Universal Demographic Correlates of Victimful Criminal Behavior." Personality and Individual Differences 9:525-48.

Ellis, Lee. 1994. "The High and the Mighty Among Men and Beast: How Universal Is the Relationship Between Height (or Body Size) and Social Status?" Pp. 93-111 in Social Stratification and Socioeconomic Inequality, Volume 2: Reproductive and Interpersonal Aspects of Dominance and Status, edited by Lee Ellis. Westport, CT: Praeger.

Ellis, Lee. 1998. "Neodarwinian Theories of Violent Criminality and Antisocial Behavior: Photographic Evidence from Nonhuman Animals and a Review of the Literature." Aggression and Violent Behavior 3:61-110.

Ellis, Lee and Anthony Walsh. 1997. "Gene-Based Evolutionary Theories in Criminology." Criminology 35: 229-76.

Farrington, David P. 1992. "Explaining the Beginning, Progress, and Ending of Antisocial Behavior from Birth to Adulthood." Pp. 253-86 in Advances in Criminological Theory, Volume 3: Facts, Frameworks, and Forecasts, edited by Joan McCord. New Brunswick, NJ: Transaction. 
Farrington, David P. 1994. "Childhood, Adolescent, and Adult Features of Violent Males." Pp. 215-40 in Aggressive Behavior: Current Perspectives, edited by L. Rowell Huesmann. New York: Plenum.

Farrington, David P. and Donald J. West. 1995. "Effects of Marriage, Separation, and Children on Offending by Adult Males." Pp. 249-81 in Current Perspectives on Aging and the Life Course, Volume 4: Delinquency and Disrepute in the Life Course, edited by Zena Smith Blau and John Hagan. Greenwich, CT: JAI Press.

Gottfredson, Michael R. and Travis Hirschi. 1990. A General Theory of Crime. Stanford, CA: Stanford University Press.

Gove, Walter R. 1985. "The Effect of Age and Gender on Deviant Behavior: A Biopsychosocial Perspective." Pp. 115-44 in Gender and the Life Course, edited by Alice S. Rossi. New York: Aldine.

Greenberg, David F. 1985. "Age, Crime, and Social Explanation.” American Journal of Sociology 91:1-21.

Grogger, Jeff. 1998. "Market Wages and Youth Crime." Journal of Labor Economics 16: Forthcoming.

Hagan, John, A. R. Gillis, and David Brownfield. 1996. Criminological Controversies: A Methodological Primer. Boulder, CO: Westview.

Hechter, Michael and Satoshi Kanazawa. 1993. "Group Solidarity and Social Order in Japan.” Journal of Theoretical Politics 5:455-93.

Hirschi, Travis and Michael Gottfredson. 1983. "Age and the Explanation of Crime." American Journal of Sociology 89:552-84.

Hirschi, Travis and Michael Gottfredson. 1985. "Age and Crime, Logic and Scholarship: Comment on Greenberg." American Journal of Sociology 91:22-27.

Hirschi, Travis and Michael Gottfredson. 1986. "The Distinction Between Crime and Criminality." Pp. 55-69 in Critique and Explanation: Essays in Honor of Gwynne Nettler, edited by Timothy F. Hartnagel and Robert A. Silverman. New Brunswick, NJ: Transaction.

Hirschi, Travis and Michael R. Gottfredson (editors.) 1994. The Generality of Deviance. New Brunswick, NJ: Transaction.

International Criminal Police Organization. Various years. International Criminal Statistics. Lyon: Interpol.

Kanazawa, Satoshi. 1998. "In Defense of Unrealistic Assumptions." Sociological Theory 16:193-204.

Laub, John H., Daniel S. Nagin, and Robert J. Sampson. 1998. "Trajectories of Change in Criminal Offending: Good Marriages and the Desistance Process.” American Sociological Review 63:225-38.

Maryanski, Alexandra and Jonathan H. Turner. 1992. The Social Cage: Human Nature and the Evolution of Society. Stanford, CA: Stanford University Press.

Mazur, Allan and Joel Michalek. 1998. "Marriage, Divorce, and Male Testosterone." Social Forces 77:315-30.

Moffitt, Terrie E. 1993. "Adolescence-Limited and Life-Course-Persistent Antisocial Behavior: A Developmental Taxonomy." Psychological Review 100:674-701.

Patterson, Gerald R. and Karen Yoerger. 1993. "Developmental Models for Delinquent Behavior.” Pp. 140-72 in Mental Disorder and Crime, edited by Sheilagh Hodgins. Newbury Park, CA: Sage.

Ridley, Matt. 1993. The Red Queen: Sex and the Evolution of Human Nature. New York: Penguin.

Rowe, David C., Alexander T. Vazsonyi, and Aurelio Jose Figueredo. 1997. "Mating-Effort in Adolescence: A Conditional or Alternative Strategy." Personality and Individual Differences. 23:105-15.

Sampson, Robert J. and John H. Laub. 1993. Crime in the Making: Pathways and Turning Points Through Life. Cambridge, MA: Harvard University Press.

Stark, Rodney. 1979. "Whose Status Counts? Comment on Tittle, Villemez and Smith." American Sociological Review 44:668-69.

Steffensmeier, Darrell J., Emilie Andersen Allan, Miles D. Harer, and Cathy Streifel. 1989. "Age and the Distribution of Crime." American Journal of Sociology 94:803-31.

Thiessen, Del and Yoko Umezawa. 1998. "The Sociobiology of Everyday Life: A New Look at a Very Old Novel." Human Nature 9:293-320.

Thornhill, Randy and Nancy Wilmsen Thornhill. 1983. "Human Rape: An Evolutionary Analysis." Ethology and Sociobiology 4:137-73.

Tittle, Charles R., Wayne J. Villemez, and Douglas A. Smith. 1978. "The Myth of Social Class and Criminality: An Empirical Assessment of the Empirical Evidence." American Sociological Review 43:643-56.

Tooby, John and Leda Cosmides. 1990. "The Past Explains the Present: Emotional Adaptations and the Structure of Ancestral Environments." Ethology and Sociobiology. 11:375-424.

van den Berghe, Pierre L. 1990. "From the Popocatepetl to the Limpopo." Pp. 410-31 in Authors of Their Own Lives: Intellectual Autobiographies by Twenty American Sociologists, edited by Bennett M. Berger. Berkeley: University of California Press.

Walsh, Anthony. 1995. Biosociology: An Emerging Paradigm. Westport, CT: Praeger.

White, Gregory L. 1981. "Some Correlates of Romantic Jealousy." Journal of Personality 49:129-47.

Wolfgang, Marvin E. 1958. Patterns in Criminal Homicide. Philadelphia: University of Pennsylvania Press.

Wright, Robert. 1994. The Moral Animal: The New Science of Evolutionary Psychology. New York: Vintage. 